\title{
Response to Differential Risk Factors of Ischemic Stroke
}

\author{
Vivian Chun Kyle Lin Stephen M. Perle \\ University of Bridgeport, College of Health Sciences, School of Chiropractic, Bridgeport, CT, USA
}

Dear Editor,

We read with interest Garg et al.'s [1] study on the risk factors and outcomes of cervical artery dissection (CeAD) in the young adult population. We were hoping that this study would provide more clarity on this important disorder. Results of the cohort study present the risk factors, prognostic factors, and outcomes associated with CeAD. Of interest, approximately $24 \%$ of ischemic strokes in the studied population were due to CeAD. The authors found significant odds ratios for migraine and cervical manipulation prior to $\mathrm{CeAD}$, with the largest odds ratios for cervical manipulation within 6 months and 2 weeks before the dissection. One is led to assume that cervical manipulation poses a risk for CeAD.

However, Garg et al. [1] acknowledge this apparent risk could be "protopathic bias," a term introduced by Horwitz and Feinstein [2]. Protopathic bias is "when an exposure is delivered in the early prodrome of a disease before it is diagnosed" as defined by Cassidy et al. [3]. There is the possibility to consider that a patient already undergoing the progression of a CeAD may visit a chiropractor and be exposed to a neck manipulation during that period. Given the fact that Garg et al. were aware of the potential for protopathic bias as the cause for the elevated risk for CeAD after cervical manipulation, why did they not test for this by including primary care physician visits and neck pain in their analysis. We believe that they

karger@karger.com

(c) 2021 S. Karger AG, Basel

www.karger.com/ced

Karger! were the first researchers who might have tested Cassidy et al.'s [4] finding.

Church et al. [5] identified the threat to the strength of a study if confounding variables are overlooked. Confounding factors are important when concluding a causal relation. In the case of CeAD and cervical manipulation, an important potential confounding variable is neck pain [5]. Furthermore, Gottesman et al. state that nonspecific symptoms such as dizziness/vertigo, headache, and neck pain are the most common and frequent clinical manifestations in patients with vertebral artery dissection [6]. Had Garg et al. [1] incorporated these into their study design, the value of these confounding factors might have been further elucidated.

Additionally, recent research has found another risk factor which Garg et al. [1] could have tested. According to Del Zotto et al. [7], there is a $>2$-fold increased risk of spontaneous CeAD if one has a history of fluoroquinolone usage within a 30-day period. We believe Garg et al. [1] missed an opportunity to corroborate or refute the effects of protopathic bias and these other potentially important but documented risk factors.

\section{Conflict of Interest Statement}

The authors have no conflict of interest to disclose.

Vivian Chun

University of Bridgeport, College of Health Sciences, School of Chiropractic 225 Myrtle Ave.

Bridgeport, CT 06604 (USA)

vchun@my.bridgeport.edu 


\section{Funding Sources}

There was no funding received.

\section{References}

1 Garg A, Bathla G, Molian V, Limaye K, Hasan D, Leira EC, et al. Differential risk factors and outcomes of ischemic stroke due to cervical artery dissection in young adults. Cerebrovasc Dis. 2020;49(5):509-15.

2 Horwitz RI, Feinstein AR. The problem of "protopathic bias" in case-control studies. Am J Med. 1980;68(2):255-8.

3 Cassidy JD, Boyle E, Côté P, Hogg-Johnson S, Bondy SJ, Haldeman S. Risk of carotid stroke after chiropractic care: a population-based

\section{Author Contributions}

V.C., K.L., and S.M.P. conceived, contributed, and approved of the final manuscript.

case-crossover study. J Stroke Cerebrovasc Dis. 2017;26(4):842-50.

4 Cassidy JD, Boyle E, Cote P, He Y, HoggJohnson S, Silver FL, et al. Risk of vertebrobasilar stroke and chiropractic care: results of a population-based case-control and case-crossover study. Spine. 2010 Mar 1; 35(5):595.

5 Church EW, Sieg EP, Zalatimo O, Hussain NS, Glantz M, Harbaugh RE. Systematic review and meta-analysis of chiropractic care and cervical artery dissection: no evidence for causation. Cureus. 2016 Feb 16;8(2):e498.

6 Gottesman RF, Sharma P, Robinson KA, Arnan $M$, Tsui M, Ladha $K$, et al. Clinical characteristics of symptomatic vertebral artery dissection. a systematic review. Neurologist. 2012 Sep;18(5):245-54.

7 Del Zotto E, Pezzini A. Use of fluoroquinolones and the risk of spontaneous cervical artery dissection. Eur J Neurol. 2019 Jul;26(7): 1028-31. 